\title{
EL TERREMOTO DE CINCHONA DEL JUEVES 8 DE ENERO DE 2009
}

\author{
Red Sismológica Nacional (RSN: UCR - ICE) \\ www.rsn.geologia.ucr.ac.cr
}

El día jueves 8 de enero de 2009 un fuerte sismo sacudió la región norte del Valle Central de Costa Rica, propiamente unos $40 \mathrm{~km}$ al norte de la ciudad capital, en la provincia de Heredia. El sismo tuvo una magnitud Mw 6,2, una profundidad de 3,6 km y está asociado a una falla ubicada en el flanco este del volcán Poás (Fig. 1). La actual actividad se inició el día miércoles 7 de enero de 2009 con un evento de magnitud 4,6 que ocurrió en la misma zona a las $10 \mathrm{am}$. La actividad de réplicas fue continua luego del terremoto y se registraron más de 1550 . Se reportaron serios daños en carreteras y caminos principalmente en la zona de Cinchona y Varablanca al norte de Heredia, viviendas y edificaciones con daños y alarma general en la población. 23 personas fallecieron. Algunas obras del Instituto Costarricense de Electricidad (ICE) ubicadas en la zona como la presas de PH Toro II y PH Cariblanco fueron afectadas parcialmente. El servicio eléctrico sufrió averías serias en la zona del epicentro y en el área metropolitana se interrumpió por una hora. Los servicios telefónicos se saturaron también por al menos unas dos horas. Históricamente la zona norte de Alajuela y Heredia ha tenido varios terremotos importantes como los de 1851 (M 6,0), 1888 (M 6,0), 1911 (M 6,1), 1912 (M 6,1) y 1955 (M 5,8). En tiempos recientes, se registró un enjambre sísmico en junio y julio del 2005 en la misma zona, también relacionado con un sistema de fallas localizado en esta zona.

RSN, 2009: El terremoto de Cinchona del jueves 8 de enero de 2009.- Rev. Geól. Amér. Central, 40: 91-95. 


\section{DATOS DEL SISMO}

HORA LOCAL: 13:21

MAGNITUD: 6,2 $\mathrm{M}_{\mathrm{w}}$ (Magnitud del momento sísmico).

PROFUNDIDAD: $3,6 \mathrm{~km}$.

UBICACIÓN: Cinchona

INTENSIDAD MÁXIMA (Escala Mercalli Modificada): IX en Cinchona e Isla Bonita

ORIGEN: fallamiento superficial de tipo oblicuo en dirección aproximadamente NorteSur, cuya ruptura se extiende por unos $12 \mathrm{~km}$ en horizontal y unos $7 \mathrm{~km}$ en su inclinación en profundidad, generando un deslizamiento promedio a lo largo del plano de falla, calculado en $30 \mathrm{~cm}$.

\section{REPORTE DE DAÑOS (FUENTE: CNE)}

25 muertos

07 desaparecidos

91 heridos

2.326 personas albergadas

25 albergues

63 misiones aéreas de rescate realizadas

249 movilizados y 15 trasladados a centros médicos

1 puente en Los Ángeles, Sarapiquí, arrasado

2 puentes en Poasito dañados

1 puente en Río Cuarto de Grecia caído

1 puente sobre el río Seco, en Bajos del Toro, se colapsó

Viviendas destruidas en Poasito, Varablanca, Sabana Redonda, Río Cuarto, Cinchona, Infiernillo, Dulce Nombre de Alajuela, Santa Rosa de Poás y Barrio Fátima de Heredia

Iglesia de Cinchona destruida.

Pérdidas estimadas en 100 millones de dólares.

La principal fuente sísmica en la zona es el fallamiento; local, dado que la otra fuente de sismos asociada al proceso de subducción de la placa del Coco, son de bastante profundidad (entre 70 y $150 \mathrm{~km}$ ). Las fallas y alineamientos que se pueden observar en las fotografías aéreas son en general de mediana longitud (menos de $20 \mathrm{~km}$ ), a excepción de las fallas San Miguel, Volcán ViejoAguas Zarcas y Zarcero, aunque algunos podrían estar total o parcialmente cubiertos por productos volcánicos recientes y en la actualidad no podemos ver la totalidad de su longitud. Todas estas fallas cortan rocas volcánicas con edades inferiores a 600 000 años y en su mayoría tienen edades inferiores a 300-100 ka, por lo que se consideran como Cuaternarias y potencialmente activas (Fig. 1).

Durante el período de 1992-2006, las estaciones de la Red Sismológica Nacional (RSN) registraron, dentro de la zona norte, un total de 1866 sismos los de los cuales 776 corresponden a sismos originados por el proceso de subducción de la placa del Coco bajo la placa Caribe y 1090 a sismos superficiales (profundidades menores a 20 $\mathrm{km}$ ) y son originados en sistemas de fallamiento local. De ellos los más importante se presentan en el cuadro 1.

Durante el periodo 2004-2006 el ICE mantuvo una red sismológica local en la zona norte para estudios de detalle de varios proyectos hidroeléctricos, con esta red se localizaron con gran precisión gran cantidad de sismos como se observa en la figura 1.

La mayor parte de los sismos se localizaron en las estribaciones norte de la cordillera Volcánica Central, con concentraciones de eventos principalmente en las cercanías del volcán Poás y en la falla Vara Blanca. En las llanuras del norte se observa cierta sismicidad que se extiende en sentido más o menos NE-SW y que podría corresponder con algunas fallas cubiertas por depósitos recientes, no descritas todavía pues no afloran en superficie.

Además de los terremotos que se han registrado en la zona de Poás y Bajos del Toro en tiempos históricos, también se han presentado varios enjambres sísmicos en 1980, 1982, 1986, 1990, 1997, 1998 y más recientemente en el 2004 y 2005. Todos estos enjambres, aunque en su mayoría son de corta duración y magnitudes moderadas, demuestran la presencia de fallas activas en la zona. 


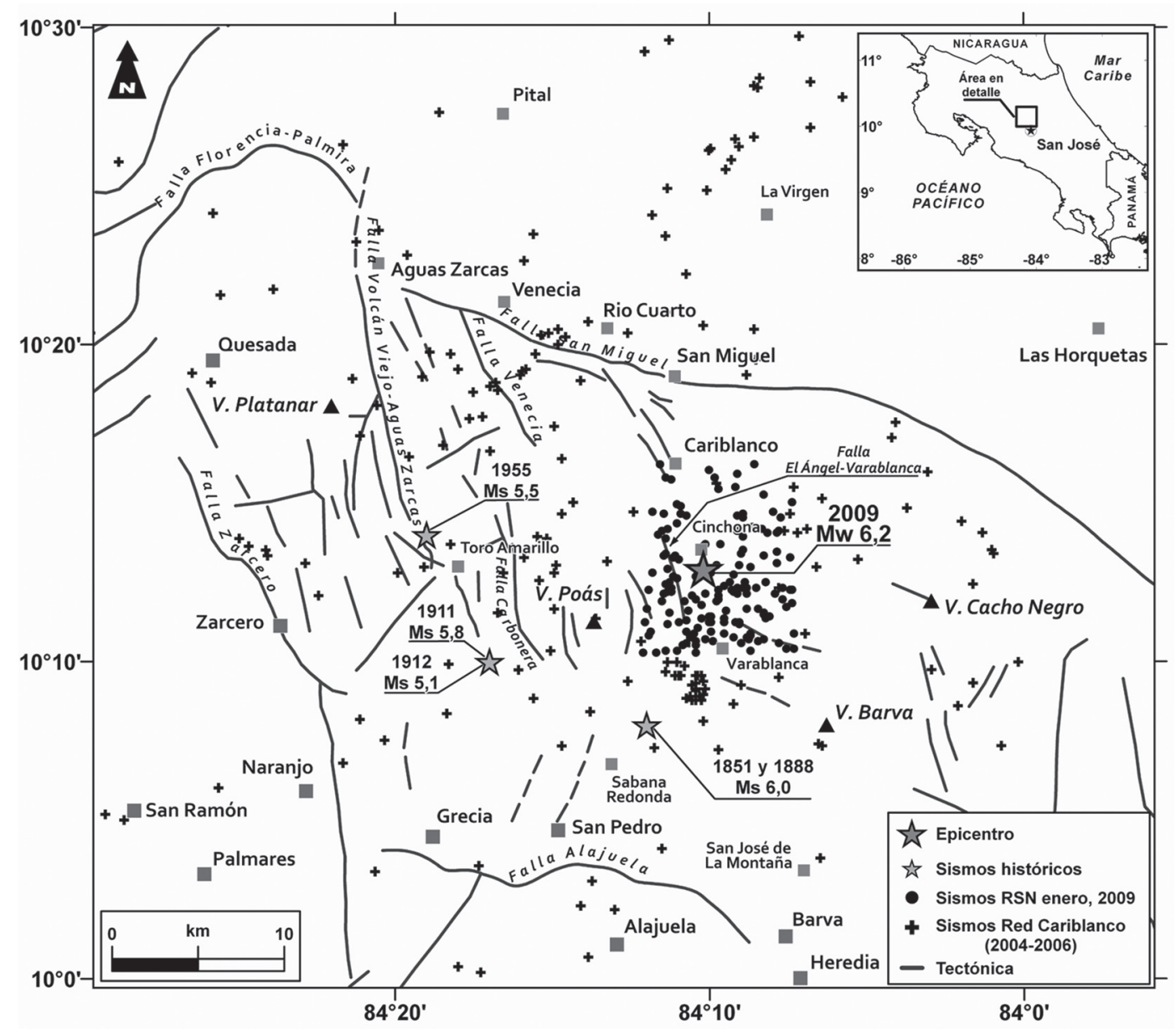

Fig. 1: Terremotos históricos, sismo principal del 8 de enero 2009 y réplicas localizados por la RSN.

\section{TERREMOTO DE CINCHONA DEL 8 DE ENERO DE 2009}

El Terremoto de Cinchona ocurrió el 8 de enero del 2009 a las 13:21 horas y tuvo una magnitud de 6,2. Este evento causó destrozos tanto por la sacudida sísmica como por los deslizamientos que fueron disparados por la vibración símica en una zona de fuertes pendientes constituida por suelos de origen volcánico saturados e inestables.

Cuando ocurre un evento sísmico grande como el de Cinchona, se debe a la ocurrencia de una ruptura en la corteza de dimensiones importantes a lo largo de una falla. Esa ruptura súbita causa una zona de inestabilidad que sigue originando sismos hasta que encuentra su punto de equilibrio. Esos sismos que ocurren luego de un sismo principal se denominan réplicas. En algunas ocasiones, pero no siempre, el sismo principal es antecedido por temblores que se denominan precursores o premonitores.

En el caso específico del Terremoto de Cinchona, se dieron tanto sismos precursores como réplicas. Un evento precursor importante ocurrió el 7 de enero del 2009 a las 10 a.m., tuvo una magnitud de 4,6. Entre esta hora y las 13:21 del día 8 ocurrieron 39 sismos. Es decir, se tienen registrados un total de 40 sismos precursores de magnitud entre 2,5 y 4,6 .

El día 8 de enero ocurrió el sismo principal de magnitud 6,2 a las 13:21. El resto del día 8 hasta la medianoche fueron registradas 62 réplicas con 


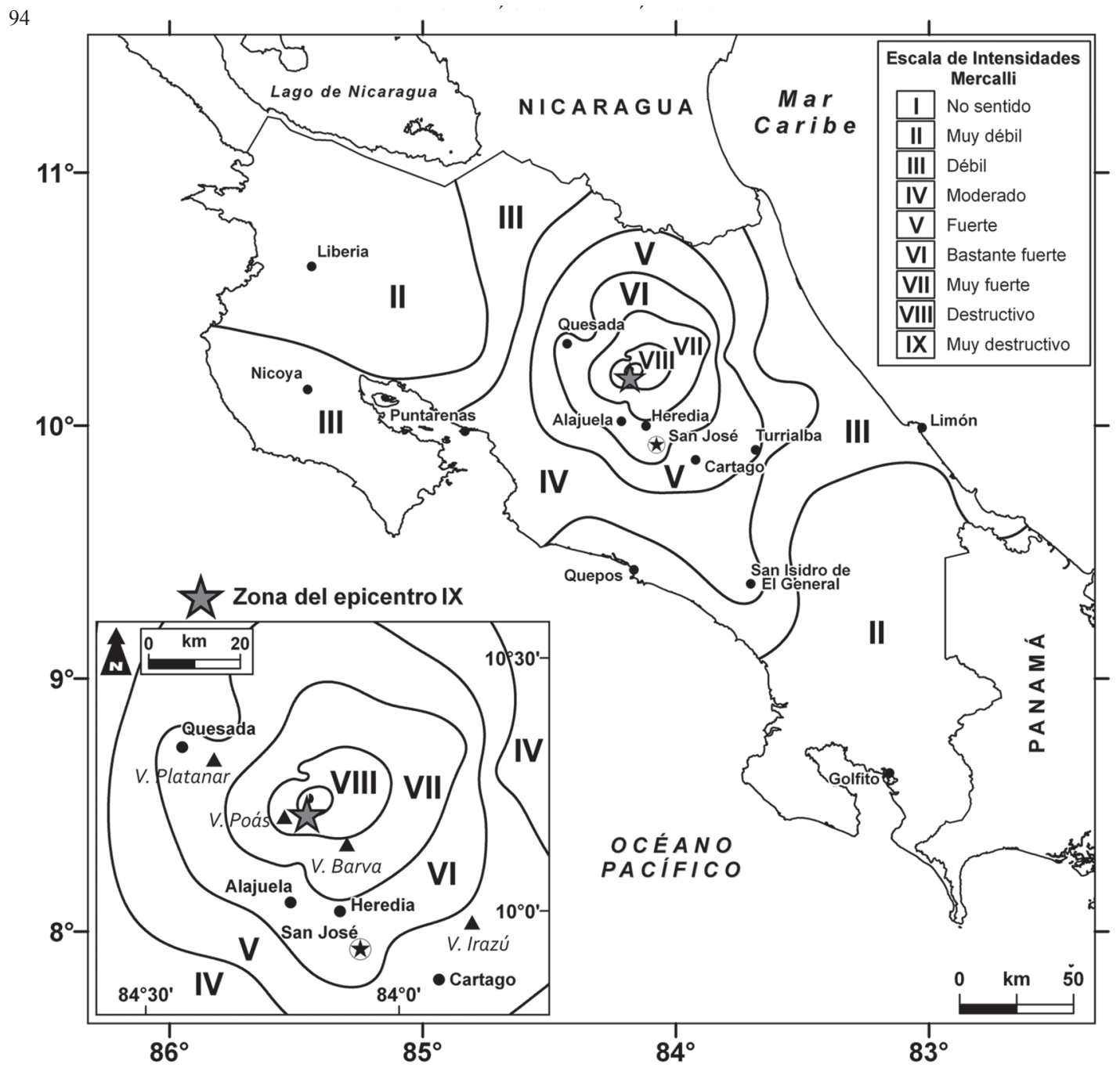

Fig. 2: Mapa intensidades Mercalli Mod. del terremoto de Cinchona (Mw 6,2)

magnitudes entre 2,5 y 4,4 en 10,6 horas. El 9 de enero se registraron 123 réplicas, el 10 de enero 57 y el 11 de enero 24, todas ellas de magnitud por encima de 2,5 y por debajo de 4,0. Es evidente de la observación de estas cifras que la cantidad de réplicas ha venido disminuyendo con el tiempo. El 12 y el 13 de enero se da una situación particular aunque normal, la gran inestabilidad tectónica que causó el terremoto del 8 de enero provoca que se dispare la ocurrencia de sismos en otras fallas vecinas, tanto hacia el norte del volcán Poás como hacia el sur en la zona de Carrizal. Por lo tanto, los sismos 18 registrados el 12 de enero y los 21 hasta las 9 horas del 13 de enero, son una mezcla entre réplicas originadas en la falla Vara Blanca-Ángel y sismos disparados en otras fallas vecinas, lo cual era de esperar y ya había sido mencionada por personal de la Red Sismológica Nacional en diferentes declaraciones a los medios de comunicación.

El terremoto del 8 de enero $2009\left(M_{w} 6,2\right)$ se produjo en la falla ubicada en el flanco este del macizo del volcán Poás. Es una falla de rumbo NNW-SSE de unos $15 \mathrm{~km}$ de extensión. La ruptura que originó el terremoto, de acuerdo a la distribución de las múltiples réplicas (más de 1500), se extiende por unos $12 \mathrm{~km}$ en la horizontal y $7 \mathrm{~km}$ en su profundidad, generando un deslizamiento promedio del plano de falla, calculado en $30 \mathrm{~cm}$.

Las intensidades máximas estimadas para este terremoto, con base en la información de campo y los daños observados fueron de IX (MM). Esta intensidad fue a nivel muy local de la población 
Cuadro 1

Sismos mayores a 4,0 en la región de estudio

\begin{tabular}{cccccccccc}
\hline Año & Mes & Día & Hr. Min & Seg. & LAT & LONG & PROF. & MAG \\
\hline 1992 & 9 & 2 & 1609 & 45,6 & $10,298^{\circ}$ & $-84,222^{\circ}$ & 4,1 & 4,1 \\
1992 & 9 & 3 & 31 & 9,8 & $10,433^{\circ}$ & $-84,409^{\circ}$ & 3,0 & 4,1 \\
1992 & 9 & 14 & 831 & 42,5 & $10,179^{\circ}$ & $-84,158^{\circ}$ & 8,5 & 4,5 \\
1993 & 4 & 26 & 635 & 18,2 & $10,287^{\circ}$ & $-84,415^{\circ}$ & 0,9 & 4 & 4,2 \\
1997 & 7 & 19 & 1425 & 30,3 & $10,228^{\circ}$ & $-84,432^{\circ}$ & 0,1 & 4,2 \\
1998 & 4 & 8 & 405 & 26 & $10,162^{\circ}$ & $-84,179^{\circ}$ & 5 & 4,2 \\
2002 & 6 & 7 & 232 & 7,3 & $10,307^{\circ}$ & $-84,248^{\circ}$ & 2,9 & 4,1 \\
2005 & 6 & 17 & 530 & 34,2 & $10,168^{\circ}$ & $-84,185^{\circ}$ & 1,8 & 4 & \\
\hline
\end{tabular}

de Cinchona en donde se estimaron aceleraciones del suelo mayores a $1 \mathrm{~g}$.

Las intensidades en las demás poblaciones en donde ocurrieron daños, como Varablanca, Poasito, Cartagos, Cariblanco, etc., fueron entre VII y VIII. Cerca de Alajuela y Heredia fueron de VI y en San José de V. Las intensidades se atenuaron rápidamente dado que el sismo fue superficial, por lo que en provincias como Puntarenas, Limón y Guanacaste fue de III y II (Fig. 2).

Es importante tener en cuenta que Costa Rica es un país que por su ubicación en una región tectónicamente muy activa es susceptible de tener actividad sísmica importante en cualquier momento, ya sea asociada al proceso de subducción de la placa del Coco bajo la placa Caribe o a fallamiento local. Por esta razón es imperativo que la población esté siempre preparada y que las construcciones se hagan siempre apegadas a las reglamentaciones del Código Sísmico y el Código de Cimentaciones que los expertos del país han desarrollado a raíz de estudios y la experiencia de muchos años. Si esto se cumple se logrará reducir en mucho los daños y las muertes que pueden ocasionar futuros terremotos en Costa Rica. 
